\title{
Photovoltaic Multi-level Inverters Technology
}

\author{
M. Sundar rajan, Madhukar Reddy Nimmala, G.Sudhagar, Kummari Shailaja, Pallavi \\ Nareddy
}

\begin{abstract}
In this paper, the three predominant styles of multilevel inverter Reviews (diode-clamped, capacitors fly, and flowing the H-Bridge inverter). Different multi-stage inverter topology that is currently to be had on the market as a ways as additives for electric integration of the PV machine also are involved. The new trend of all this topology are trying to find to lessen prices, the dimensions of the inverter and losses via reducing the range of switches and capacitors and keep a fairly high output voltage step at least just like the previous topology.
\end{abstract}

Keywords-Photovoltaic, Multi-level inverter, Diode clamped, flying capacitor, cascaded H-Bridge inverters.

\section{INTRODUCTION}

Since the Nineteen Nineties replacing gadgets, as an example, GTO thyristors and IGBT transistors have been extensively applied in Power Electronic Converters. These Converters are at present grouped into:

a) Rectifiers - Converters that convert an info rotating voltage and modern-day into yield direct voltage and cutting-edge;

b) Inverters - Converters that convert enter direct voltage and modern-day into yield changing voltage and cutting-edge;

c) DC voltage Converters (Choppers) - Converters that convert input direct voltage and current of one incentive into yield direct voltage and contemporary of various qualities;

d) $\mathrm{AC}$ Converters - Converters that convert input vitality with one parameters (substituting voltage, modern, variety of ranges, recurrence) into changing yield energy with one-of-a-kind parameters.

This paper explores the acknowledgment of a Multilevel Inverter (MI) that has an area with type (b) - Inverters. The regular unmarried-stage Inverter creates not unusual rectangular voltage on its yield. Power Electronic switchers are changed to 2 facts voltages - tremendous and bad. This kind of Inverter is known as a -stage Inverter. Electronic Switchers are worried with the aid of full information DC voltage for this situation. The Electronic Switcher voltage strain may be reduced utilizing an arrangement association

Revised Manuscript Received on September 14, 2019.

M. Sundar rajan, Associate Professor, Department of Control and Instrumentation, Faculty of Electrical and Computer Engineering, Arbaminch University, Ethiopia

Madhukar Reddy Nimmala, Asso.Prof, Department of EEE, Siddhartha Institute of Technology \& Sciences, Narapally, Ghatkesar, Hyderabad, Telangana, India.

G.Sudhagar, Professor, Department of ECE, Siddhartha Institute of Technology \& Sciences, Narapally, Ghatkesar, Hyderabad, Telangana, India

Kummari Shailaja, Assist. Prof, Department of EEE, Siddhartha Institute of Technology \& Sciences, Narapally, Ghatkesar, Hyderabad, Telangana, India.

Pallavi Nareddy, Assist. Prof, Department of EEE, Siddhartha Institute India. of Technology \& Sciences, Narapally, Ghatkesar, Hyderabad, Telangana,

or a Multilevel Inverter. Regular Inverters are utilized in low-voltage electric equipment up to at least one $\mathrm{kV}$.

For medium and excessive voltage gear greater than $1 \mathrm{kV}$, an arrangement association of GTO/IGBT or a Multilevel

Inverter is implemented. The three-degree Inverter is the Multilevel Inverter with the most modest range of degrees. The benefits of 3-degree Inverter topology over normal twolevel topology are:

- The voltage over the switches is just a single part of the DC source voltage;

- The replacing recurrence can be diminished for a similar changing misfortunes;

- The higher yield modern song are diminished by a similar exchanging recurrence. Staggered Inverters find out programs in new zones of medium-and excessive-voltage applications,

for example recurrence Inverters for high voltage customizable pace drives, Inverters for excessive-voltage compensators, excessive-voltage Unified Power Flow Controllers (UPFC), and excessive-voltage Active Power channels, and so forth. Voltage wellsprings of the following ranges can be acknowledged as remoted resources or as voltage capacitor dividers. Isolated sources require further Power Hardware. The significant trouble in Multilevel Inverters with capacitor dividers is the first-rate viable manage manner for voltage adjustment with out extra Power Hardware. The most famous types of MI are Diode Clamped Multilevel Inverters (DCMI) and Flying Capacitor Multilevel Inverters (FCMI). For a 3-level topology, just the two styles of MI may be planned with out a remoted voltage resources or helper Power circuits. Papers [6] and [7] reflect onconsideration on these two forms of Multilevel Inverters from distinctive perspectives. The correlation became acknowledged for a similar yield Powers. The numerical fashions for the two forms of In-verters were researched within the Simulink program. This correlation indicated that 3-degree DCMI calls for the all out limit of all capacitors to be in any event a couple of times lower than 3-level FCMI so that you can accomplish a comparable capacitor voltage swinging. Consequently the DCMI arrangement is considered as step by step possible for three-degree MI.

In any case, for a better wide variety of tiers than 3 in DCMI, the capacitor voltage can't be adjusted making use of just the control system. Extra circuits or unfastened resources are required. For example, paper

[3] depicts the adjustment of capacitor voltage in fivedegree DCMI making use of the propelled device together with assistant circuits. Despite what is probably predicted the voltage can be balanced out utilizing simply the manipulate method in FCMI for all levels. Staggered 
Inverters with more than one degrees are essentially utilized in high-voltage packages for the voltage greater noteworthy than $10 \mathrm{kV}$.The motivation at the back of this paper is to introduce the aftereffects of a hypothetical document and the affordable acknowledgment of a five-stage FCMI. After a concise depiction of five-degree FCMI topology, we gift the reproduction and check outcomes. The undertaking and exploratory aftereffects of five-stage FCMI are done on a model, supplied with $200 \mathrm{~V}$ DC source. Both of those outcomes display that a five-degree yield voltage is created and the capacitor voltage is balanced out utilizing just the manage technique. Five-level FCMI is examined here in light of the fact that lone this process can alter the capacitor voltage using just the control technique.

\section{Photovoltaic framework staggered Inverters}

Staggered inverters can orchestrate a better yield voltage contrasted with the voltage rating of every fused exchanging machine and don't forget a far smoother yield wave.Also the consonant bending is reduced. Various kinds of staggered inverters are accessible in recent times. There are 3 precept staggered inverters; diode-clasped inverter, flying

capacitor inverter and route $\mathrm{H}$-Bridge inverters.

\section{Flying Capacitor Inverter}

The flying capacitor inverter association is an choice in evaluation to the diode-clipped assortment. In any case, resulting from the flying capacitor association, voltage over an open switch is pressured with the aid of methods for bracing capacitors as opposed to diodes indicates the unmarried leg of a three diploma of flying capacitor inverter. In the occasion that the information DC interface is Vdc and the

flying capacitor works in a situation of equalization, in order to accomplish equivalent strengthen voltages at yield voltage, the clipped capacitor should be directed at VC1 = $\mathrm{Vdc} / 2$ due to a 3-degree inverter. The braced capacitor for a 4 stage inverter have to be managed to $\mathrm{VC} 2=2 \mathrm{VC} 1=$ $2 \mathrm{Vdc} /$ three. It have to be stated thatalong with the growth in nice performed with a 4 level inverter, voltage weights on the exchanging parts are reduced through a element of Vdc/6. In spite of the truth that the yield voltage

stages in the flying capacitor inverter design are very just like the diode-cinched inverter; there are some changing states on hand to perform a comparable level. These are alluded to as extra changing states. Such repetition offers the adaptability to modify the clasped capacitor

voltages with the stop aim that they may deliver substitute cutting-edge circles via the capacitors .Table II is depicting the exchanging situations of the flying capacitor inverter.

The possible switching states of flying capacitor inverter

\begin{tabular}{|c|c|}
\hline Onl- State switclles & $V_{0}$ \\
\hline$\overline{S W 1}$ and $\overline{S W 2}$ & 0 \\
\hline$S w 2$ and $\overline{S W 1}$ & $0.5 V_{d c}$ \\
\hline$S w 1$ and $\overline{S W 2}$ & $0.5 V_{d c}$ \\
\hline Sw1 and SW2 & $V_{d c}$ \\
\hline
\end{tabular}

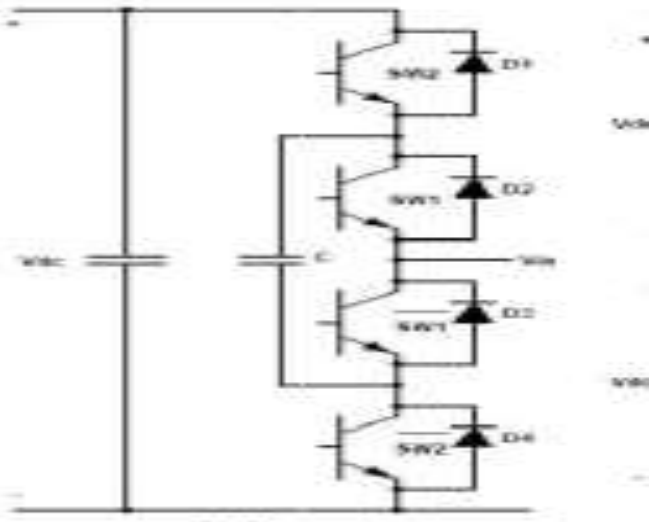

Fig.shows flying capacitor

\section{BASIC FEATURES \& METHODOLOGY}

Topology consists of diodes, capacitors and switching devices.

- Although theoretically this topology has been designed to offer countless diploma, but due to practical boundaries handiest offer up to six voltage levels.

- Each leg consists of a device this is typically transistor switching.

- Each inverter leg consists of cells which can be connected in series to the nest.

- Each cellular has one capacitor and electric switches. The strength transfer is a aggregate of a transistor is connected to the anti-parallel diode.

- Unlike a diode clamped inverter, it makes use of a capacitor to clamp topology.

- An inverter with $\mathrm{N}$ cells may have a switch $2 \mathrm{~N}$ and $\mathrm{N}+$ 1 one of a kind voltage tiers inclusive of zero.

- We also can have a bad voltage stage, and so all we are able to say that $\mathrm{N}$ multilevel inverter cells can provide $2 \mathrm{~N}+$ 1 voltage ranges.

- in the direction of the weight capacitor has a lower voltage.

- The capacitor towards the supply voltage (VDC) has a higher voltage.

- The variety of ranges relies upon on the range of switched on each limb.

- It is likewise called Imprecated Cell Inverter.

- They are known as Flying Capacitor Multilevel Inverter, because the capacitor floats with appreciate to ground potential.

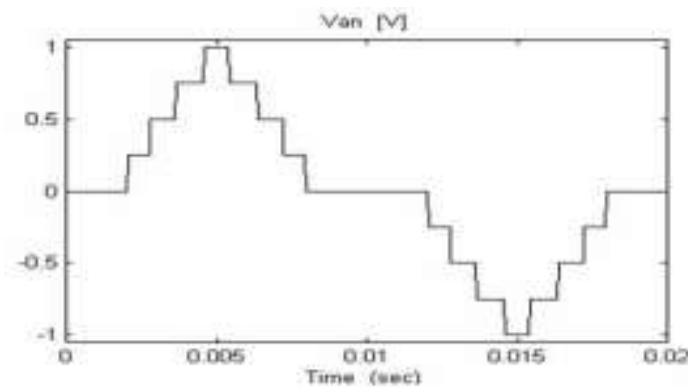

Fig.converter output 


\section{VOLTAGE BALANCING OF CAPACITORS \& RESULTS}

One of the large focal points of utilizing a Flying Capacitor Multilevel Inverter is its capability to work at voltages higher than the blocking off restrict of each energy cellular comprising of diode and replacing component.

Current co-powerful of each appendage is equal and inverse in extremity. That is the motive there's no net alternate inside the charge of capacitors.

The mobile and capacitor voltage comparison is kept up interior a sheltered band and consequently there's no opportunity of unbalancing the capacitor voltages.

\section{Exchanging Strategy}

To include a sinusoidal waveform at the yield, changing procedure must be characterized. It could be very primary. Each voltage is carried out at yield with a specific electric edge. Cautious use of the brink gives low consonant twisting and required sufficiency at the yield.

More than one replacing strategies are reachable for a solitary voltage level. Three conditions need to be pursued for the ideal selection:

For each adjustment in the kingdom, simply one switch flow should be authorised.

Capacitor's voltage parity ought to be kept up.

All the exchanging devices should be utilized further.

Preferred position

Each branch can be broke down independently and completely.

\section{Detriment}

Pre charging of capacitors is essential and troublesome.

End

All things considered flying capacitor staggered inverter topology is acclaimed topology which has its very very own blessings. The quantity of devices applied inside the hardware may be very good enough and is additionally monetarily managed. This staggered inverter offers tremendous electricity fine execution.

\section{REFERENCES}

1. (2014). Modest Solar Power Is Fueling Global Renewable Energy Growth:Report . To be had:http://www.Huffingtonpost.Com/2014/04/07/solar based powerrenewable-vitality growth_n_5107150.Html.

2. B.J.M. De Vries, D.P. Van Vuuren and M.M. Hoogwijk, "Renewableenergy resources: Their worldwide capability for the main portion of the 21 stcentury at a international degree: A coordinated technique," Energy Policy, vol. 35, no. Four, pp. 2590-2610, Apr. 2007.

3. Z. Zhao, M. Xu, Q. Chen, J. S. Jason Lai, and Y. H. Cho, "Derivation,analysis, and execution of a boost buck converter-primarily based highefficiencypv inverter,"IEEE Trans. Power Electron., vol. 27, no. Three, pp.1304-1313, Mar. 2012.

4. N. Mohan, T. M. Undeland, and W. P. Robbins,Power Electronics Converters, Applications and Design, 0.33 ed. New York, NY, USA:Wiley, 2003.

5. W. Nook, "Inverters-Critical photovoltaic parity offramework parts: Status, troubles, and new thousand years openings," Prog. Photovolt. Res. Appl., vol. Eight, no. 1, pp. 113-126, 2000.
6. F. Blaabjerg, Z. Chen, and S. B. Kjaer, "Power hardware as productive interface in scattered energy age frameworks," IEEE Trans. Power Electron., vol. 19, no. 5, pp. 1184-1194, Sep. 2004.

7. P. P. Rodriguez, M. M. D. Bellar, R. R. S. Mũ nozAguilar, S. S. BusquetsMonge, and F. F. Blaabjerg, "Staggered clipped staggered converters (MLC)," IEEE Trans. Power Electron., vol. 27, no. Three, pp. 10551060, Mar. 2012

8. K. Ilves, A. Antonopoulos, S.Norrga, and H.- .P. Nee, "another regulation method for the measured staggered converter allowing essential replacing recurrence," IEEE Trans. Power Electron., vol.27, no. Eight, pp. 34823494, Aug. 2012.

9. H. Akagi, "Characterization, wording, and usage of the measured staggered route converter (MMCC)," IEEE Trans. Power Electron.,vol. 26, no. Eleven, pp. 31193130, Nov. 2011

10. E. Babaei and S. H. Hosseini, "New fell staggered inverter topology with least wide variety of switches,"Energy Convers. Manage.,vol. 50, no. Eleven, pp. 2761-2767, Nov. 2009.

11. S. Mekhilef and M. N. Kadir, "Voltage manipulate of three-arrange pass breed staggered inverter using vector transformation,"IEEE Trans. Power Electron., vol. 25, no. 10, pp. 2599-2606, Oct. 2010.

12. A. A. Boora, A. Nami, F. Zare, A. Ghosh, and F. Blaabjerg, "Voltagesharing converter to supply singledegree topsy-turvy fourleveldiode clasped inverter with excessive electricity element loads," IEEE Trans. Power Electron., vol. 25, no. 10, pp. 2507-2520, Oct. 2010.

13. J. Rodriguez, S. Bernet, P. Steimer, and I. Lizama, "An assessment on nonpartisan point cinched inverters," IEEE Trans. Ind. Electron., vol. Fifty seven, no. 7, pp. 2219-2230, Jul. 2010.

14. J. I. Leon, R. Portillo , S. Vazquez, J. J. Padilla , L. G. Franquelo and J.M. Carrasco , "Straightforward sure together manner to cope with increase a length space tweak methodology for single-stage staggered converters"," IEEE Trans. Ind. Elec., vol. 55, no. 9, pp.3239 - 3248, 2008.

15. L. G. Franquelo, J. Rodriguez, J. I. Leon, S. Kouro, R. Portillo, and M.A. M. Prats, "The time of staggered converters suggests up," IEEE Ind. Elec. Mag. , vol. 2, no. 2, pp. 28-39, Jun. 2008

16. S. Kouro, M. Malinowski, K. Gopakumar, J. Pou, L. G. Franquelo, B. Wu, J. Rodriguez, M. A. Perez, and J. I Leon, "Late advances and contemporary makes use of of staggered converters," IEEE Trans. Power Elec. , vol. 57, no. Eight, pp. 2553-2580, Aug. 2010

17. J. Liu, K. W. E. Cheng, and Y. Ye, "A Cascaded Multilevel Inverter Based on Switched-Capacitor for High-Frequency AC Power 